\title{
Analysis of price behavior patterns for revenue projections: statistical tests of a copper price time series
}

\author{
Marcia Athayde Matias \\ University of Brasília \\ Cesar Augusto Tiburcio Silva \\ University of Brasília \\ Leonardo Vieira \\ University of Brasília
}

\begin{abstract}
In analyzing the projected cash flow of an investment, especially when the main product is a commodity, defining future revenue as a function of the price behavior of this commodity is a widely debated question among academics and financial analysts. This study carries out econometric evaluations based on a historical copper-price series, aiming to verify whether these prices follow some behavior pattern already reported in the literature, especially mean reversion and geometric Brownian motion (GBM). Tests were performed for stationarity, autocorrelation, normality and linearity. These results indicate that copper prices in the interval studied have not followed any identified behavior pattern, suggesting that the models normally used in financial projections have a weak capacity to forecast future copper prices.
\end{abstract}

Key-words: prices, commodity, behavior patterns, copper

Received in 11/09/2005; revised in 20/09/2005; accept in 11/11/2005.

\section{* Corresponding authors:}

Marcia Athayde Matias Mestrado em Ciências Contábeis Universidade de Brasília

Adress: Campus Universitário Darcy Ribeiro - Prédio da FA - $2^{\circ}$ Andar - Salas B1-02, Asa Norte,

70910-900 - Brasilia - DF-

Brazil

Email:mathayde@unb.br

Telephone: 3133758448
Cesar Augusto Tiburcio Silva Doutor em Controladoria e Contabilidade Universidade de Brasília

Adress: Campus Universitário Darcy Ribeiro - Prédio da FA - $2^{\circ}$ Andar - Salas B1-02, Asa Norte, 70910-900 - Brasilia DF-Brazil

Email: cesartiburcio@unb.br Telephone: (61) 32731105

\section{Leonardo Vieira} Doutor em Controladoria ContabilidadeUniversidade de Brasília

Adress: Campus Universitário Darcy Ribeiro - Prédio da FA

- $2^{\circ}$ Andar - Salas B1-02, Asa Norte, 70910-900 - Brasilia DF-Brazil Email:vieira.leo@gmail.com Telephone: (61) 32731105 


\section{INTRODUÇÃO}

ne of the big dilemmas in assessing projects, particularly those based on discounted

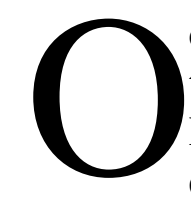
cash flows, is to define the basic premises that will support the projected results. In this sense, defining future revenue is an important and delicate step in the process. Revenue, being a function of the sale price, is strongly dependent on factors exogenous to the firm, and this dependence is more pronounced if the firm produces a commodity.

This article's objective is to analyze the precision of future price projections of a particular commodity, to identify whether the long-term price behavior follows some defined or definable pattern and if there are conditions to formulate a mathematical equation to explain this movement, as a way to obtain more accurate premises to evaluate investments.

The commodity studied here is copper. According to statistics from the Associação Brasileira de Cobre [Brazilian Copper Association] (2004), until 2003 the product contributed negatively to the Brazilian trade balance. In 2004, copper for the first time moved over to the positive side, due to exports from new undertakings in the state of Pará.

This study will describe the characteristics of the main types of commodity price movements, investigating, among others, whether copper prices in the period studied take the form of a random walk, geometric Brownian motion or a mean reverting trend, identifying which, if any, of them is predominant, relying particularly on the studies of Dixit and Pindyck (1993).

This paper is organized in three parts: Part I contains the introduction, methodology and delimitation of the study; Part II addresses commodity prices in general and copper prices in particular, along with general aspects of the stochastic behavior of variables; and Part III analyzes the behavior of copper prices and presents the conclusions.

The importance of this study is to contribute to the discussion of the use of strong premises to assess investments. As new works are developed and knowledge is disseminated and debated, more companies will be able to evaluate their investments more accurately, which will certainly help increase the credibility of the investment projects in Brazil and consequently make a positive contribution to its development.

\section{METHODOLOGY}

This study is eminently quantitative in nature, since it seeks correlations between independent variables in an attempt to construct an equation representative of a previously observed empirical result, namely copper price fluctuations. It is supported by a review of the literature, consisting of secondary sources, prior studies and opinions of specialists on the matter. It is essentially a case study in that it focuses on a single segment, the commodity copper.

The data under analysis were published by the Commodity Exchange of New York (COMEX), a subsidiary of the New York Mercantile Exchange (NYMEX), and consist of a historic series of daily closing copper prices. The definition of the sample size was dictated by the availability of these data, which started being systematized and published on the Internet starting from September 2001. Therefore, the sample consists of 40 months, from September 2001 to December 2004, containing 808 observations.

The results of this study apply specifically to undertakings involving copper and cannot be generalized to all commodities, since the factors that influence the market for each 
commodity are different. Nevertheless, the study can serve as a base for new empirical studies involving other commodities.

\section{COMMODITIES AND COPPER}

The general meaning of "commodity" is simply "an article of commerce." More specifically, it can be defined as "a particular type of merchandise in its raw or primary product state that has commercial importance, as is the case of coffee, cotton, tin and copper, among others" (Sandroni). In practice, the concept of commodity is generally associated with a unspecialized product, made through a widely diffused technology, produced and transported in large volumes.

Copper has been used to make utensils and tools for over seven thousand years, and has been alloyed with tin to make bronze for more than five thousand years. Until the middle of the nineteenth century, trade in copper was essentially controlled by Great Britain, which had the leading technology to treat the ore to produce the metal. However, that century new mines were discovered in the United States, Chile and Australia. This fact, combined with the development of new concentration technologies allowing economic use of ores with lower metal content, resulted in the global expansion of copper production in the twentieth century (NYMEX, 2005).

Until 2003 Brazil produced very little copper ore, instead importing copper concentrate (with $25 \%$ to $30 \%$ metal content, attained after initial ore processing) from Chile, Argentina and Portugal to supply companies producing cathode (metallic copper) and semifinished products in the country. With the opening of new mines in the state of Pará, the preliminary expectation of Companhia Vale do Rio Doce, which is making major investments in the region, are that output will be some 140 thousand metric tons in 2005, rising to 650 thousand t/year of copper concentrate by 2010 (Rosa, 2003), enough to supply the internal market, with a positive effect on Brazil's trade balance.

Copper prices are dictated by the London Metal Exchange (LME) and the Commodity Exchange of New York (COMEX), with most transactions being in the form of futures contracts. The prices are quoted in US\$ cents/pound ${ }^{2}$ of copper in concentrate.

\section{STUDIES OF THE BEHAVIOR OF COMMODITY PRICES}

Fama and French (1987), relying on the "theory of storage", conducted a study of 21 commodities, among them copper, trying to identify some elements that influence future prices. At a first step of the study, the authors determined a linear equation in which the dependent variable "future prices" was a function of "current spot prices" plus a determined "interest rate", and a dummy variable to identify whether the product had seasonal price characteristics. The model showed low capacity to forecast copper prices.

At a second step of the study, they established a new linear equation whose dependent variable "prices of future contracts" was a function of "current spot prices" plus a "premium for the expected variation in time". This model demonstrated evidence of the influence of the premium expectation, but did not turn out to be statistically significant when tested for copper. The authors assumed a normal distribution of the variables and did not perform specific tests for stationarity and autocorrelation.

Gibson and Shwartz (1989), analyzing an oil price time series over the period 1984 to 1988 , constructed an equation to project future prices in which they assumed that spot prices 
and the instantaneous net revenue of contracts follow a stochastic process with a strong meanreverting pattern. This equation showed satisfactory results for short-term projections.

In their study on the equilibrium of asset prices, Bessembinder et al. (1995) detected a mean reversion trend in the behavior of various asset prices, among them petroleum, agricultural products, metals and financial assets. This behavior pattern was stronger in agricultural than in metals prices. Just as did Fama and Gibson, Bessembinder et. al. used prices of commodity futures contracts as proxies to estimate the spot price.

Dixit and Pindyck (1993) in their book presented a deflated historic series of copper prices from 1870 to 1990 , which did not present unit roots, indicating stationarity. These authors argued that the mean reverting process is slow, and that only by using very long time series of more than 30 or 40 years can this commodity's price behavior in fact be observed.

According to Slade (2001), there is real evidence that commodity prices follow a mean reversion pattern, even though it is easier to assume that these prices follow geometric Brownian motion or other nonstationary process.

McMillan and Speight (2001) analyzed the daily volatility of nonferrous metals prices between 1971 and 2000, decomposing the volatility into short and long terms. Under this approach, they isolated some factors that contribute to short-term volatility, such as speculative movements, arrival of new information and hedge positions, along with fundamental factors that contribute to long-run volatility, such as physical availability of the products and the law of supply and demand. This decomposition into short and long terms was made possible through the use of a modified GARCH model, called component-GARCH (or CGARCH). The results demonstrated that the half life of short-term volatility shocks, due to market factors, typically does not last more than eight days, while the half life of long-term volatility shocks, caused by fundamental factors, is roughly 190 days, so that metals prices only slowly revert to the mean. They found evidence of a link between the volatility of metals prices, a trend led in the first moment by aluminum prices and in a second moment by copper prices. More specifically, the long-term volatility, while it exhibits a long-term memory, in fact is stationary and has a tendency to revert to the mean.

\section{STOCHASTIC BEHAVIOR PATTERNS}

Considering the objective of this study, to analyze the behavior pattern of copper prices, it is interesting to recall, among the various stochastic behavior patterns prices can assume, those more frequently cited in the observed literature.

The stochastic process provides a mathematical representation of how a system evolves over time (Terceiro, 2003). According to Dixit and Pindyck (1993), a stochastic process of a variable is defined by a probability law for the evolution $x_{t}$ of a variable $x$ over time $t$. Hence, for data at moments $t_{1}, t_{2}, t_{3}$, the probability can be calculated of the occurrence of $x_{1}, x_{2}, x_{3}$.

Stochastic processes can take on a stationary behavior, when the mean and variance of the variable are constant in time, and nonstationary, when the expected value of the variable $x$ grows without bound and the variance increases with $t$. Regarding the occurrence of $x$, it can vary in discrete or continuous form in time and in state.

A stochastic process can assume several behaviors:

- A random walk, stationary or not, in which the variable $x$ assumes a pattern of constant upward and downward jumps with the same probability.

- If this behavior presents a trend, it is classified as random walk with drift. 
- Considering that the upward or downward jump can assume a continuous or random pattern, with normal distribution, zero mean and standard deviation $\square$ then the behavior of $\mathrm{x}$ will be classified as a time-discrete and continuous-state stochastic process.

- Another example of a stochastic process is the first-order autoregressive process, called $\mathrm{AR}(1)$ for short, which is determined by the following formula:

$$
\mathrm{x}_{\mathrm{t}}=\mu+\phi_{1} \mathrm{x}_{\mathrm{t}-1}+u_{t}
$$

where: $\mu$ and $\phi$ are constants and $u_{t}$ is the error term.

The $\mathrm{AR}(1)$ process is additionally referred to as a mean reversion process, because over the long run, $x_{t}$ tends to a constant value.

The behaviors described above, namely random walk, in discrete or continuous time, with or without drift, and the AR(1) process, all satisfy the Markov Property ${ }^{3}$, and because of this are also called Markov processes.

Brownian motion, or the Wiener process ${ }^{4}$, is a nonstationary stochastic process in continuous time that has three important properties: 1) it is a Markov process; 2) it has independent increments of change over the time interval; and 3) changes in the process at any moment of a finite time interval assume a normal distribution, in which the variance increases linearly with time. According to Dixit and Pindyck (1993), these conditions are restrictive, and they suggest that very few variables in the real world can really be modeled with a Wiener process, unless adaptations are made in the model.

The equation that describes the Wiener process is:

$$
\Delta \mathrm{z}=\in_{\mathrm{t}} \sqrt{ } \Delta \mathrm{t}
$$

where: $\epsilon_{\mathrm{t}}$ is an uncorrelated random variable with normal distribution, mean of zero and standard deviation of 1 .

By adapting the original Wiener model, it is possible to describe Brownian motion with drift from the following equation:

$$
d x=\alpha d t+\sigma d z
$$

where: $d z$ is the increment of change, $\alpha$ is the growth trend parameter and $\sigma$ is the variance parameter, constants.

Generalized Brownian motion, or the Ito Process, is a generalization of the original motion, given by the equation below:

$$
d x=\mathrm{a}(x, t) d t+\mathrm{b}(x, t) d z
$$

where: $d z$ is the increment of change and $a(x, t)$ and $b(x, t)$ are known, nonrandom functions. The variables $a$ and $b$ are also called growth trend and variance parameters, functions of the current time and state.

The parameters $a(x, t)$ and $b(x, t)$ are called, respectively, the instantaneous expected growth rate and the instantaneous variance rate.

Also according to Dixit and Pindyck, particular cases of behavior can be derived from the concept of Brownian motion: 1) geometric Brownian motion (GBM); and 2) mean-reverting processes.

In GBM, the trend and variance parameters are given respectively by:

$$
\begin{aligned}
& a(x, t)=\alpha x \\
& b(x, t)=\sigma x
\end{aligned}
$$

When substituted in the Ito Process equation, these yield:

$$
d x=\alpha x d t+\sigma x d z
$$

In GBM with drift, $x$ assumes a lognormal distribution. Then, with $\mathrm{F}(x)=\ln x$, we have a normal distribution whose expected value of $x$ does not depend on the variance, and is given by the equation: 


$$
\varepsilon[x(t)]=x_{0} \mathrm{e}^{\alpha \mathrm{t}}
$$

While in GBM prices tend to move far from the starting point, in the behavior pattern known as mean-reverting trend even though prices rise and fall randomly, in the long run they tend to return to the marginal cost of production. The simple mean-reverting process is denominated the Ornstein-Uhlenbeck Process, and is given by the equation:

$$
d x=\eta(\mathrm{x}-\mathrm{x}) \mathrm{dt}+\sigma d z
$$

where: $d z$ is a Wiener increment, $\eta$ is the velocity of reversion and $\mathrm{x}$ is the normal level of $x$, to which $\mathrm{x}$ tends to revert.

In the mean-reverting process, the expected value of $\mathrm{x}$ depends on the difference between $\mathrm{x}$ and $\mathrm{x}$, so if the expected value of $\mathrm{x}$ is greater (smaller) than the expected value of $\mathrm{x}$, it is more probable that the prices will fall (rise) in the short run. This means that this type of behavior does not have independent increments, even though it satisfies the Markov properties.

By calculating the mean and variance of $d x$, the expected value of $x$ is given by the following equation:

$$
\varepsilon\left[x_{t}\right]=x+\left(x_{0}-x\right) \mathrm{e}^{-\eta t}
$$

These are the behavior patterns of commodity prices for comparison against the chosen copper price time series, to see if one of them can explain the empirical data.

\section{Analysis of the time series chosen: copper prices}

I carried out the analyses here with data from a time series covering the period from September 2001 to December 2004, all told 40 months and 808 observations of copper closing prices (as published at the COMEX site), relying on the statistical software tools of Excel and Eviews.

As can be seen in the graph below, there is an upward oscillating trend with periodic spikes. Copper prices began at US\$ 0.673/lb at the start of September 2001 and reached US $\$ 1.487 / \mathrm{lb}$ at the end of December 2004 , with a mean of US $\$ 0.75 / \mathrm{lb}$ and standard deviation of 0.082 .

\section{Graph 1 - Detail of the variation of copper prices from September 4, 2001 to December 30, 2004.}

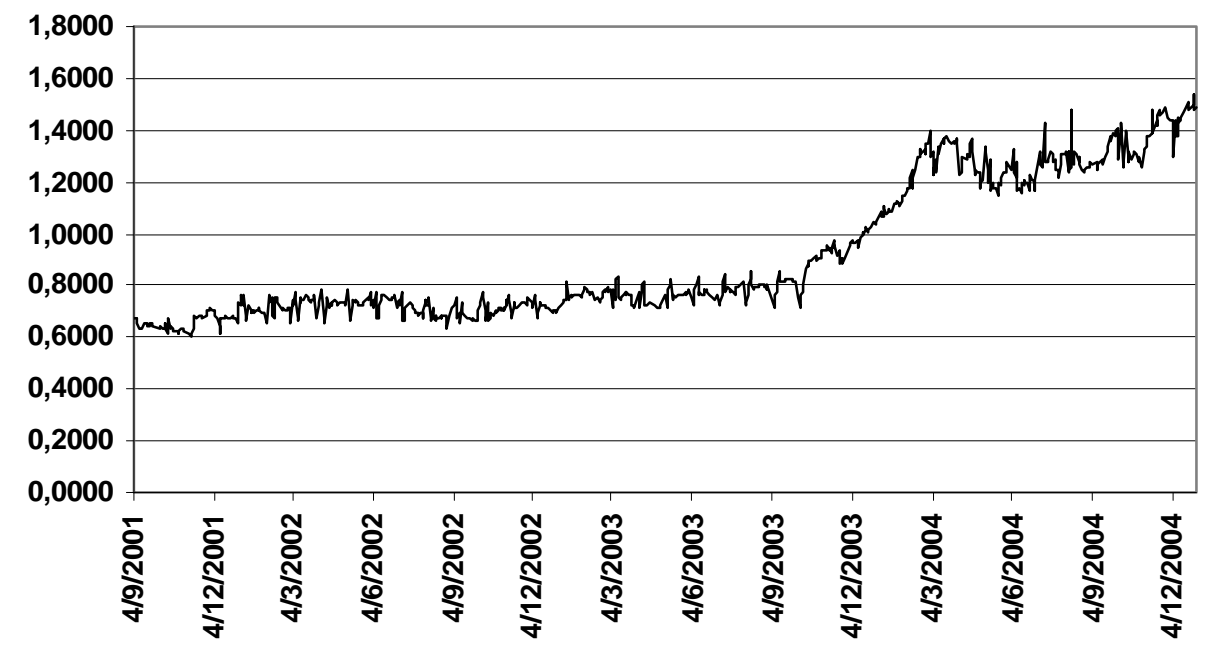


I calculated the return of the prices through the natural logarithm of the quotient of the closing prices for two consecutive days. The mean return was $0.085 \%$ per day, reaching $61.34 \%$ in the total sample period.

I did not deflate the time series because the United States' share of the world market is only $8 \%$ of production and $15 \%$ of consumption, so considering that copper is a world commodity, and that inflation in the U.S. in the period was below $3 \%$ a year while the return attained $61.34 \%$, the impact of American inflation on prices is negligible 5 .

Graph 2 - Detail of the return of prices between September 4, 2001 and December 30, 2004.

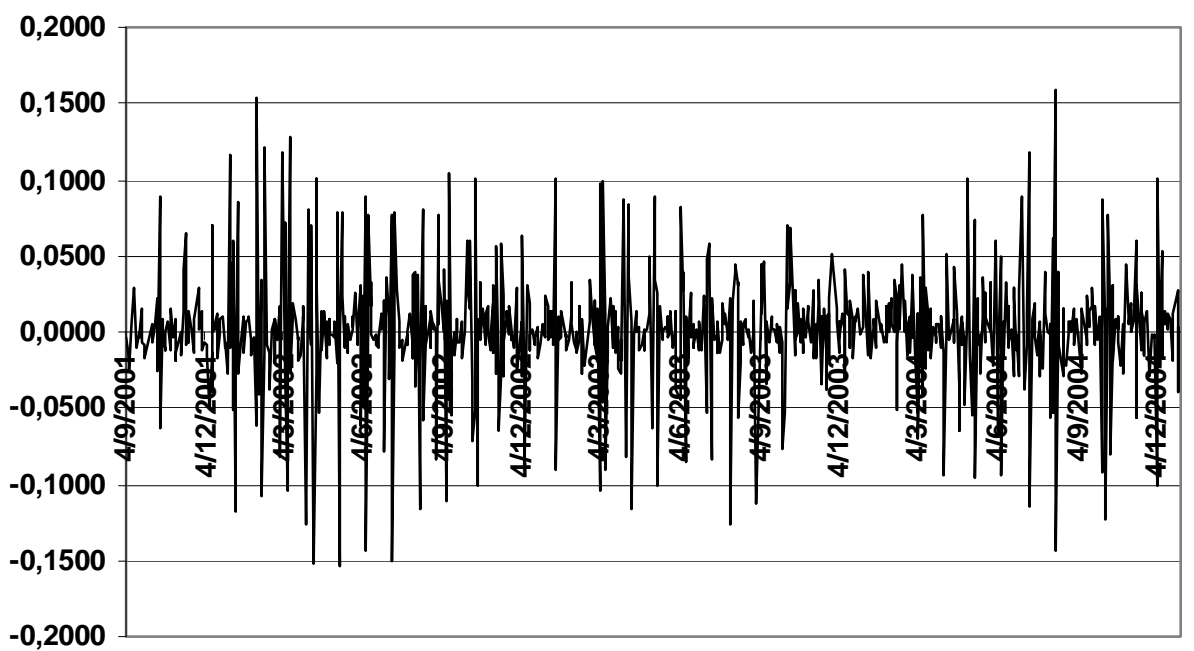

\section{$\underline{\text { Unit root test }}$}

In order to determine the equation that best represents the behavior of copper prices, I first analyzed whether this series has unit roots.

The presence of one or more unit roots indicates a time series is nonstationary, i.e., the values tend to increase with time, assuming different patterns, which are: random walk, random walk with drift, or a process with a deterministic tendency.

The test used here to identify unit roots is the Augmented Dickey-Fuller (ADF). Given a stochastic equation:

$\mathrm{H}_{\square} \phi=0$; there are unit roots.

$$
\mathrm{x}_{\mathrm{t}}=\mu+\phi_{1} \mathrm{x}_{\mathrm{t}-1}+u_{t}
$$

$\mathrm{H}_{1:} \phi<0$; there or no unit roots.

\section{Results:}

According to the tests run in Eviews, the statistical series presented one unit root. Conducting the test again from the first difference of the series, $\mathrm{H}$ could not be rejected.

The implication of this result is acceptance that the series takes on a random walk type pattern, in detriment to a mean-reverting trend. Even though the sample size can be a bias to cast doubt on this result, Slade (2004) warns that while some studies have shown nonstationary patterns, others have evidenced that prices tend to the mean. Put to the question, Slade (2004) admits that the tests for presence of unit roots in price series generate conflicting results. 


\section{Definition of the best $A R$ model and tests for autocorrelation}

Autoregressive (AR) models are those that best represent historic series, as the one analyzed here. Hence, by analyzing the statistical results of various AR series, and also by running moving average (MA) tests through the Eviews program, it is possible to identify which model is most representative of the influence of past prices on current prices of copper. This testing is important because it allows identifying whether the price behavior has some "memory", or if it indeed satisfies the Markov property.

It is possible to detect the existence of autocorrelation by plotting the graphs of an autocorrelation function (ACF) and partial autocorrelation function (PACF), which indicate, respectively, whether there is a correlation between a current value of $\mathrm{x}$ and its immediately previous values $(x-1 ; x-2 \ldots)$, while the PACF analyzes the existence of correlation between $x$ and its non immediately prior values $(x-3 ; x-5 \ldots)$, eliminating the effects that the intermediate lags can cause.

Besides plotting the ACF and PACF, it is possible to run statistical tests to detect the linear dependence in a time series, individually or jointly.

Individually means to evaluate the influence of each past price (lag) on the current price, by constructing a confidence interval (two-tailed) at 5\% significance, using the equation:

where: $\mathrm{T}$ is the number of observations.

$$
+1,96 * 1 / \sqrt{ } \mathrm{T}
$$

To carry out the joint test, i.e., to see whether determined lags of past prices jointly influence the current price, the so-called Ljung-Box test can be used, more commonly known as the $Q$-statistic test.

According to Brooks (2002), the Q-statistic for a series with $K$ lags is given by:

$$
\mathrm{Q}^{*}=\mathrm{T}(\mathrm{T}+2) \Sigma_{\mathrm{m}}
$$

where: $\mathrm{T}$ is the sample size, $\mathrm{m}$ is the maximum distafice betweern the lags, $\square_{\mathrm{k}}$ is the

The hypotheses, for both the individual and joint results, are:

$\mathrm{H}_{0}: \tau_{1}=0 ; \tau_{2}=0 ; \tau \ldots=0 ; \tau_{808}=0$; there is no correlation between the variables.

$\mathrm{H}_{1}: \tau \neq 0$; there is correlation between the variables.

\section{Results:}

From analyses with the first difference of the time series, a necessary procedure to remove the effect of the unit root on the series and permit the tests to be run by the least squares method, I identified the AR(6) model as the one that best represents current copper price values. This means that the current prices were influenced by up to six lags in the series, which implies not accepting the Markov property.

Then I plotted the ACF and PACF graphs, and results of the Ljung-Box test, considering 20 degrees of freedom in 808 observations, for which the critical value from the of the $\mathrm{X}^{2}$ table is 31.410 , obtaining the results below.

Analyzed individually, with the exception of the sixth autocorrelation coefficient, which fell outside the confidence interval constructed, the first to fifth time lags, when analyzed in isolation, did not turn out significant in relation to the $\mathrm{H}_{0}$.

Analyzed jointly to the sixth lag, the null hypothesis could not be rejected, that there was no correlation between the lagged variables. Regarding this apparently contradictory aspect, in which a strong indication of autocorrelation was observed at two moments and at a third moment there was no indication of autocorrelation, Brooks (2002), observing a similar case, attributed the fact to the low power of a single significant variable in a set in which five lags show themselves to be insignificant. 


\section{Test of normality}

Brownian motion has as a premise the normal distribution of the variables in time, while series that assume geometric Brownian motion have a lognormal distribution. Thus, this test will complete the information necessary to try to find the best model to predict copper prices. Brooks (2002) presents the Bera-Jarque normality test as that most used. This test enables analyzing the variables under two aspects: asymmetry and kurtosis. The first permits measuring the extent to which the distribution has symmetry around its mean. The second compares the sample's distribution of frequencies against the normal distribution (Laponni, 2000). In this sense, the normal distribution is symmetric and mesokurtic.

The Bera-Jarque test is given by the following equation:

$$
\mathrm{W}=\mathrm{T}\left[\left(\mathrm{b}^{2}{ }_{1}+/ 6\right)+\left(\mathrm{b}_{2}-3\right)^{2} / 24\right]
$$

where: $\mathrm{T}$ is the sample size, and $\mathrm{b}_{1}$ and $\mathrm{b}_{2}$ can be estimated using the residuals of one regression.

The hypotheses posed are:

$\mathrm{H}_{0}: \mathrm{W}=3$; distribution normal;

$\mathrm{H}_{1}: \mathrm{W} \neq 3$; distribution not normal.

\section{Results}

$\mathrm{H}_{0}$ was rejected in favor of $\mathrm{H}_{1}$. According to the tests run by Eviews, the distribution was leptokurtic and slightly asymmetric to the left. At a second moment, the tests were performed with the price return series, which presented the same results and can be visualized in the graphs below.

Graph 3 - Output of Eviews of the price distribution curve.

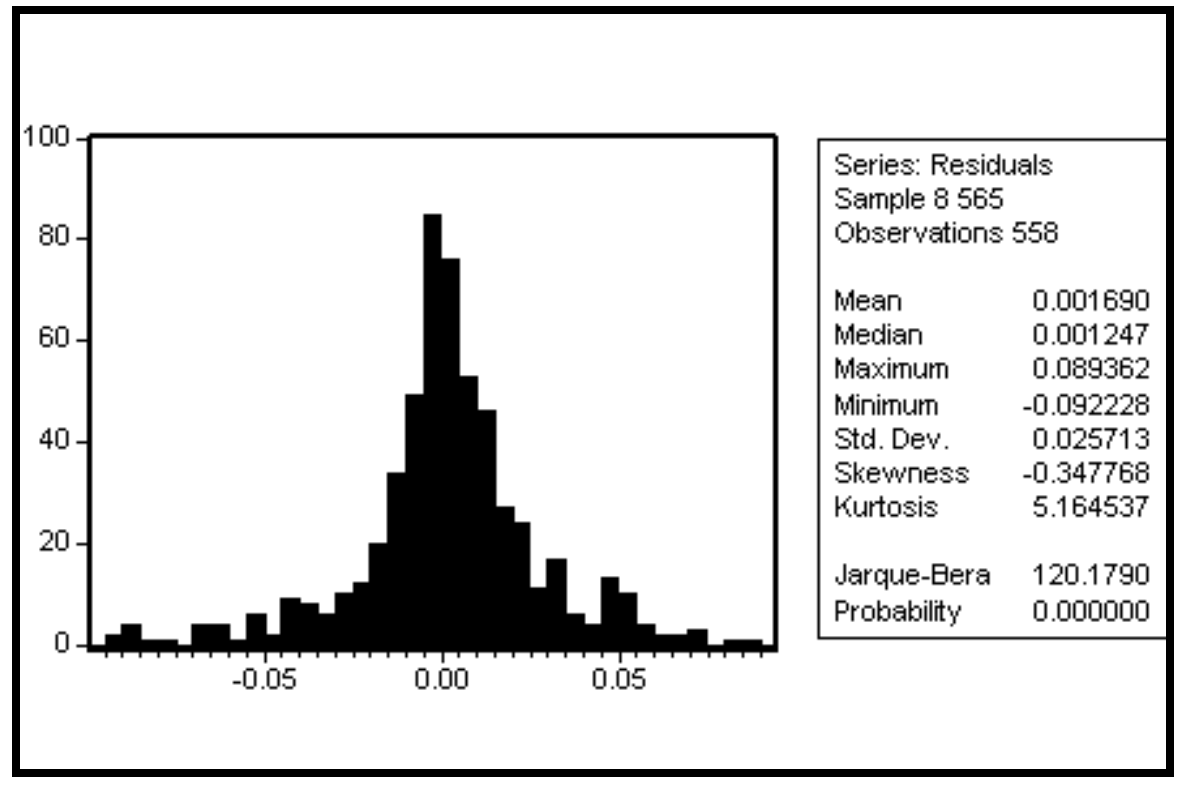


Graph 4 - Output of Eviews of the distribution curve of the returns.

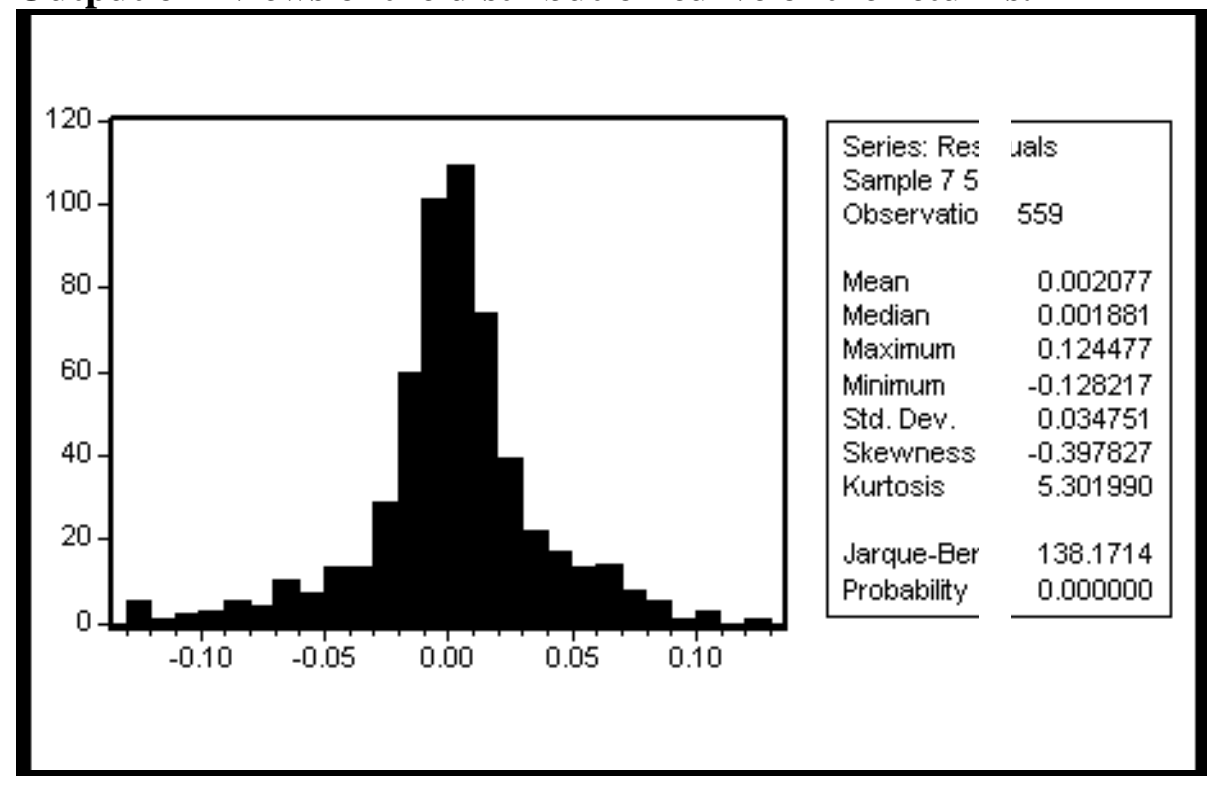

Test for linearity

Once it is detected that the distribution is not normal, it is necessary to test the time series for linearity. The most usual test is the Brock, Dechert, Scheinkman and LeBaron (BDS), which is employed to test whether the random variables that compose a series are independent and identically distributed (IID). This test can detect various situations in which the variables are IID, such as stationarity, non-linearity and deterministic chaos (Brooks, 2002). The test is based on the concept of the correlation integral $C_{m} \square$, and was run in Eviews, version 4.1.

In this test, the hypotheses are:

$\mathrm{H}_{0}$ : The time series has IID variables: model has linear characteristics;

$\mathrm{H}_{1}$ : The time series does not have IID variables: model has non-stationarity, non-linearity or deterministic chaos characteristics.

\section{Results:}

The tests were performed twice, the second activating the bootstrap function, for small samples, giving the same results.

For the 5\% significance level, the $\mathrm{H}_{0}$ was accepted for the IID characteristic, even though the result of the correlogram pointed to a leptokurtic distribution pattern.

\section{General interpretation of the tests}

The tests performed suggest that:

- The model is not stationary;

- Current prices are influenced by past prices;

- The distribution is not normal, instead assuming a leptokurtic form with some asymmetry to the left;

- The residuals of the variables of the time series analyzed are independent and identically distributed, suggesting that equation representing the series is linear.

Slade (2004) argues that results of statistical tests can cause conflicts at the time of identifying the most representative model. This is the case of this series, which takes on a peculiar behavior, with characteristics that do not jibe with some of the presuppositions of the models described above. 
To permit better visualization of the results, I prepared the reference table below, comparing the characteristics found in this series with the main characteristics of mean reversion and geometric Brownian motion.

\begin{tabular}{|c|c|c|}
\hline \multicolumn{3}{|c|}{$\begin{array}{l}\text { Comparison among the characteristics found in the series with the main } \\
\text { characteristics of mean reversion and geometric Brownian motion. }\end{array}$} \\
\hline $\begin{array}{c}\text { Geometric Brownian } \\
\text { Motion }\end{array}$ & Mean Reversion & Copper Price Series \\
\hline Lognormal distribution & Normal distribution & Leptokurtic distribution \\
\hline Nonstationary & Stationary & Nonstationary \\
\hline $\begin{array}{l}\text { Satisfies the Markov } \\
\text { property }\end{array}$ & $\begin{array}{l}\text { Satisfies the Markov } \\
\text { property }\end{array}$ & $\begin{array}{l}\text { Does not satisfy the } \\
\text { Markov property }\end{array}$ \\
\hline Linear & Linear & Linear \\
\hline
\end{tabular}

On this subject, Mandelbrot (2004) argues there is an old financial orthodoxy grounded on two basic assumptions: that prices are statistically independent and that their distribution assumes the form of the normal curve. However, the facts demonstrate the contrary: price variations are far from being normally distributed and many series are correlated with their past prices, with different patterns of "memory": short, long, periodic. And this contradicts the random walk model.

These facts make it difficult to fit the copper price series into a conventional pattern. It is much like trying to square a circle. Indeed, the difficulty of finding a mathematical model that represents the series, combined with the fact that the market is unpredictable because it is influenced by various factors, such as population growth, exhaustion and discovery of reserves, industrialization in emerging economies and financial speculation itself, makes it nearly impossible to build a mathematical equation that correctly projects the variation of future prices.

\section{Conclusion.}

The results of this study suggest that the price of copper in the period analyzed did not follow any specific behavior pattern. Instead, it had characteristics of many patterns, such as Brownian motion and nonlinear forms of behavior, making it impossible to define an equation to represent the movement or prices correctly. This suggests that the models used conventionally in financial projections have low predictive power for future prices.

In this context, an interesting source for new studies could be to formulate equations based on models, such as panel data for linear series, which better capture the relationship between present and past prices, while also permitting including the influence of exogenous variables on the price.

Other statistical models developed more recently, such as GARCH models and their variations, or the multifractal model, also are an option for future research.

Of course, it is simply not possible to divine the future. But using a more suitable model that minimizes the subjective aspects involved in price projections can significantly improve the ability to predict future revenues in analyzing investments.

In its essence, this study harks back to the discussion of paradigms in scientific research. Some established theories remain as important references to a historic understanding of the 
evolution of science, but the behavior of prices needs to be studied under new perspectives and theories, to the benefit of future projections and undertakings, and hence the population at large.

\section{Notes}

1- One pound $(1 \mathrm{lb})=0.454 \mathrm{~kg}$ or 454 grams.

2- This property assumes that the probability distribution for $\mathrm{x}_{\mathrm{t}-1}$ depends exclusively on $\mathrm{x}_{\mathrm{t}}$ and not what occurred before $x_{t}$, i.e., only the present value is relevant to forecast the future one. The Markov property is important because it simplifies the analysis of a stochastic process.

3- As Dixit and Pindyck cite in their book, the name Brownian movement originates from 1827, after the botanist Robert Brown observed and described the motion of small particles suspended in a liquid. In 1905 Albert Einstein proposed a mathematical theory to describe this motion, but it was Norbert Weiner who developed the subject with more rigor in 1923.

4- According to information from the Brazilian Copper Association and the Institute of Applied Economic Studies. 


\section{References}

ASSOCIAÇÃO BRASILEIRA DE COBRE. Anuário Estatístico do Cobre 2004. Disponível em: 〈http://www.procobre.org.br>

BESSEMBINDER, H.; COUGHENOUR, J. F.; SEGUIN, P. J.; SMOLLER, M. M. Mean Reversion in Equilibrium Asset Price: Evidence From the Futures Term Structure. The Journal of Finance. vol. 50, n. 1, March 1995.

BROOKS, C. Introductory Econometrics for Finance. Cambridge University Press. United Kingdom: 2002.

CHOWDHURY, A. R. Futures Market Efficiency: Evidence for Cointegration Tests. The Journal of Futures Markets. v. 11, n. 5, October 1991, pp. 577-589.

Companhia Vale do Rio Doce. Rio de Janeiro, Brazil. Available at:

$<$ http://www.cvrd.com.br>

DIXIT, A. K.; PINDYCK, R. S. Investment Under Uncertainty. Princeton University Press.

New Jersey, USA: 1993.

FAMA, E. F.; FRENCH, K. R. Commodities Future Price. Some Evidence of Forecast Power, Premiums and Theory of Storage. The Journal of Business, v. 60, n.1, January 1987.

GIBSON, R.; SCHWARTZ, E. S. Stochastic Convenience Yield and the Pricing of Oil Contingent Claims. The Journal of Finance. V. 45. n. 3, July 1990.

LAPPONI, J. C. Estatística Usando Excel. Lapponi Treinamento e Editora Ltda. São Paulo: 2000.

MCMILLAN, D. G.; SPEIGHT, A. E. H. Non-ferrous Metals Price Volatility: a component analysis. Resource Policy. v. 27, 2001, pp.199-207.

MANDELBROT, B.; HUDSON, R. L. Mercados Financeiros Fora de Controle: a Teoria dos Fractais Explicando o Comportamento dos Mercados. Editora Campus. Rio de Janeiro: 2004.

New York Mercantile Exchange. USA. Available at: 〈http://www.nymex.com>

ROSA, M. E. Os Minerais e o Brasil. Revista Ciênciaonline. Year II, n. 06, March-May 2003. Available at: <http://www.cienciaonline.org/revista/02_06/geologia/>

SANDRONI, P. Novo dicionário de Economia. Ed. Best Seller. Available at: <http://www.ens.ufsc.br/dicionario.htm>.

SLADE, E. M. Valuing Managerial Flexibility: An Application of Real-Option Theory to Mining Investments. Journal of Environmental Economics and Management. n. 41, 2001, pp.193-233.

; THILLE, H. Commodity Spot Price: An Exploratory Assessment of Market-Structure and Forward-Trading Effects. September 2004. Available at:

<www2.warwick.ac.uk/fac/soc/economics/staff/faculty/slade/wp/>

TERCEIRO, A. Métodos Probabilísticos de Pesquisa Operacional. UFBA:2003. Disponível em: 〈http://twiki.im.ufba.br/bin/view/MAT160/ProcessosEstocasticos>

The New Merriam-Webster Dictionary. Merriam-Webster Inc., Publishers, Massachusetts, USA: 1989. 


\section{APPENDICES}

\section{Appendix A - Unit root tests}

In level.

First difference

\begin{tabular}{|c|c|c|c|c|}
\hline ADF Test Statistic & -13.96459 & \multicolumn{2}{|c|}{$1 \%$ Critical Value* } & -3.44440 \\
\hline & & \multicolumn{2}{|c|}{$5 \%$ Critical Value } & -2.86700 \\
\hline & & \multicolumn{2}{|c|}{$10 \%$ Critical Value } & -2.56970 \\
\hline \multicolumn{5}{|c|}{$\begin{array}{l}\text { "MacKinnon critical values for rejection of hypothesis of a unit root. } \\
\text { Augmented Dickey-Fuller Test Equation } \\
\text { Dependent Variable: D(PRICE,2) } \\
\text { Method: Least Squares } \\
\text { Date: } 03 / 05 / 05 \text { Time: } 00: 22 \\
\text { Sample(adjusted): } 8 \text { 808 } \\
\text { Included observations: } 800 \text { after adjusting endpoints }\end{array}$} \\
\hline Variable & Coefficient & Std. Error & t-Statistic & Prob. \\
\hline $\mathrm{D}(\operatorname{PRICE}(-1))$ & $-2,366,812$ & 0.169487 & $-1,396,459$ & 0.0000 \\
\hline $\mathrm{D}(\mathrm{PRICE}(-1), 2)$ & 0.967827 & 0.150844 & $6,416,079$ & 0.0000 \\
\hline $\mathrm{D}(\operatorname{PRICE}(-2), 2)$ & 0.678666 & 0.127144 & $5,337,781$ & 0.0000 \\
\hline $\mathrm{D}(\mathrm{PRICE}(-3), 2)$ & 0.426399 & 0.100650 & $4,236,457$ & 0.0000 \\
\hline $\mathrm{D}(\operatorname{PRICE}(-4), 2)$ & 0.238022 & 0.072564 & $3,280,173$ & 0.0011 \\
\hline $\mathrm{D}(\operatorname{PRICE}(-5), 2)$ & 0.103651 & 0.042462 & $2,441,040$ & 0.0150 \\
\hline $\mathrm{C}$ & 0.001709 & 0.001100 & $1,552,956$ & 0.1210 \\
\hline R-squared & 0.671111 & Mean deper & ndent var & $3.85 E-05$ \\
\hline Adjusted R-squared & 0.667530 & S.D. depenc & dent var & 0.044835 \\
\hline S.E. of regression & 0.025852 & Akaike info & criterion & -4460395 \\
\hline Sum squared resid & 0.368247 & Schwarz cri & terion & -4406147 \\
\hline Log likelihood & $1,251,450$ & F-statistic & & 1873896 \\
\hline Durbin-Watson stat & $2,005,206$ & Prob(F-stati & stic) & 0.000000 \\
\hline
\end{tabular}

\section{Appendix B - Correlation of the Variables}

Analysis of statistical results in various autoregressive (AR) series, through the Eviews program.

\begin{tabular}{|c|c|c|c|c|}
\hline ADF Test Statistic & 0.105011 & \multicolumn{2}{|c|}{$1 \%$ Criticalvalue ${ }^{*}$} & $-3,4444$ \\
\hline & & \multicolumn{2}{|c|}{$5 \%$ Criticalvalue } & $-2,8670$ \\
\hline & & \multicolumn{2}{|c|}{ 10\% Criticalvalue } & $-2,5697$ \\
\hline \multicolumn{5}{|c|}{$\begin{array}{l}\text { "MacKinnon critical values for rejection of hypothesis of a unit root. } \\
\text { Dependent Variable: } D(P R I C E) \\
\text { Method: Least Squares } \\
\text { Date: } 03 / 05 / 05 \text { Time: } 00: 17 \\
\text { Sample(adjusted): } 7808 \\
\text { Included observations: } 801 \text { after adjusting endpoints }\end{array}$} \\
\hline Variable & Coefficient & Std. Error & t-Statistic & Prob. \\
\hline PRICE(-1) & 0.001518 & 0.014456 & 0.105011 & 0.9164 \\
\hline $\mathrm{D}(\mathrm{PRICE}(-1))$ & -0.390665 & 0.044598 & -8.759 .750 & 0.0000 \\
\hline $\mathrm{D}(\mathrm{PRICE}(-2))$ & -0.274282 & 0.046750 & -5866949 & 0.0000 \\
\hline $\mathrm{D}(\mathrm{PRICE}(-3))$ & -0.230062 & 0.046766 & -4919456 & 0.0000 \\
\hline $\mathrm{D}(\mathrm{PRICE}(-4))$ & -0.161563 & 0.045933 & -3517382 & 0.0005 \\
\hline $\mathrm{D}(\mathrm{PR} I \mathrm{CE}(-5))$ & -0.095028 & 0.042927 & -2213736 & 0.0273 \\
\hline C & 0.000451 & 0.010856 & 0.041585 & 0.9668 \\
\hline R-squared & 0.150142 & Mean depen & dent var & 0.000795 \\
\hline Adjusted R-squared & 0.140905 & S.D. depeno & ent var & 0.028020 \\
\hline S.E. of regression & 0.025971 & Akaike info & criterion & -4451235 \\
\hline Sum squared resid & 0.372318 & Schw arz cr & iterion & -4397062 \\
\hline Log likelihood & 1.251 .120 & F-statistic & & 1625341 \\
\hline Durbin-Watson stat & 2.013 .732 & Prob(F-stat & & 0.000000 \\
\hline
\end{tabular}




\begin{tabular}{|c|c|c|c|c|}
\hline $\begin{array}{l}\text { Dependent Variable: } \\
\text { Method: Least Squar } \\
\text { Date: 03/05/05 Tim } \\
\text { Sample(adjusted): } 8 \\
\text { Included observation } \\
\text { Convergence achiev }\end{array}$ & $\begin{array}{l}\text { (PRICE) } \\
00: 44 \\
8 \\
800 \text { after ad } \\
\text { after } 2 \text { itera }\end{array}$ & $\begin{array}{l}\text { usting endpoir } \\
\text { ions }\end{array}$ & & \\
\hline Variable & Coefficient & Std. Error & t-Statistic & Prob. \\
\hline $\mathrm{AR}(1)$ & -0.395136 & 0.042464 & $-9,305,285$ & 0.0000 \\
\hline $\mathrm{AR}(2)$ & -0.284225 & 0.045362 & $-6,265,781$ & 0.0000 \\
\hline $\mathrm{AR}(3)$ & -0.247013 & 0.046273 & $-5,338,221$ & 0.0000 \\
\hline $\mathrm{AR}(4)$ & -0.183244 & 0.046280 & $-3,959,498$ & 0.0001 \\
\hline $\mathrm{AR}(5)$ & -0.129752 & 0.045336 & $-2,862,020$ & 0.0044 \\
\hline $\mathrm{AR}(6)$ & -0.100153 & 0.042456 & $-2,358,966$ & 0.0187 \\
\hline R-squared & 0.155150 & \multicolumn{2}{|c|}{ Mean dependent var } & 0.000763 \\
\hline Adjusted R-squared & 0.147498 & \multicolumn{2}{|c|}{ S.D. dependent var } & 0.028035 \\
\hline S.E. of regression & 0.025885 & \multicolumn{2}{|c|}{ Akaike info criterion } & $-4,459,612$ \\
\hline Sum squared resid & 0.369858 & \multicolumn{2}{|c|}{ Schwarz criterion } & $-4,413,113$ \\
\hline Log likelihood & $1,250,232$ & \multicolumn{2}{|l|}{ F-statistic } & $2,027,416$ \\
\hline Durbin-Watson stat & $2,003,745$ & \multicolumn{2}{|c|}{ Prob(F-statistic) } & 0.000000 \\
\hline \multirow[t]{2}{*}{\begin{tabular}{|l} 
Inverted AR Roots \\
\end{tabular}} & $.49+.54 \mathrm{i}$ & $.49-.54 i$ & $-.10-.65 \mathrm{i}$ & $-.10+.65 \mathrm{i}$ \\
\hline & $-.59-.30 \mathrm{i}$ & $-.59+.30 \mathrm{i}$ & & \\
\hline
\end{tabular}

Tests for ACF, PACF and Q-statistic.

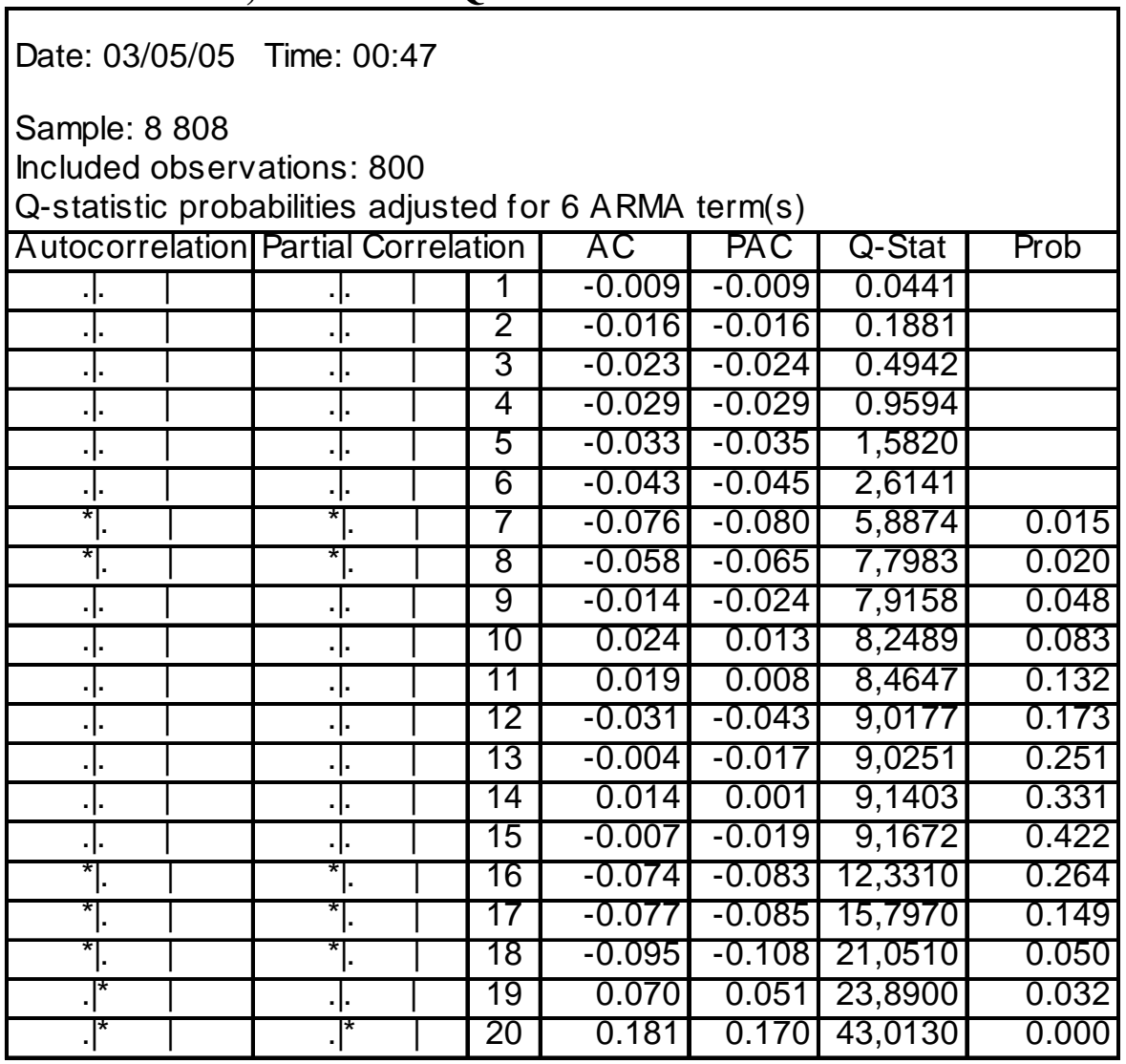


Appendix C - BDS Test for Linearity

BDS Test for PRICES

Date: 03/09/05 Time: 15:10

Sample: 1808

Included observations: 808

\begin{tabular}{|l|l|l|l|l|l|}
\hline Dimension & BDS Statistic & Std. Error & z-Statistic & Normal Prob. & Bootstrap Prob. \\
\hline 2 & 0.157484 & 0.004286 & 3.674 .610 & 0.0000 & 0.0000 \\
\hline 3 & 0.263059 & 0.006835 & 3.848 .941 & 0.0000 & 0.0000 \\
\hline 4 & 0.330859 & 0.008169 & 4.050 .157 & 0.0000 & 0.0000 \\
\hline 5 & 0.372762 & 0.008547 & 4.361 .167 & 0.0000 & 0.0000 \\
\hline 6 & 0.398068 & 0.008275 & 4.810 .289 & 0.0000 & 0.0000 \\
\hline \multicolumn{2}{|l|l|l|l|}{ Raw epsilon } & 0.1026931 & & & \\
\hline \multicolumn{2}{|l|}{ Pairs within epsilon } & 225173.00 & V-statistic & 0.7053740 & \\
\hline \multicolumn{2}{|l|}{ Triples within epsilon } & 98918295. & V-statistic & 0.5484427 & \\
\hline Dimension & $\mathrm{C}(\mathrm{m}, \mathrm{n})$ & $\mathrm{c}(\mathrm{m}, \mathrm{n})$ & $\mathrm{C}(1, \mathrm{n}-(\mathrm{m}-1))$ & $\mathrm{c}(1, \mathrm{n}-(\mathrm{m}-1))$ & $\mathrm{c}(1, \mathrm{n}-(\mathrm{m}-1))^{\wedge} \mathrm{k}$ \\
\hline 2 & 104425.00 & 0.657729 & 112292.00 & 0.707280 & 0.500245 \\
\hline 3 & 98.150 .000 & 0.620405 & 112265.00 & 0.709626 & 0.357346 \\
\hline 4 & 92.666 .000 & 0.587829 & 112238.00 & 0.711985 & 0.256970 \\
\hline 5 & 87.777 .000 & 0.558804 & 112213.00 & 0.714368 & 0.186042 \\
\hline 6 & 83.524 .000 & 0.533631 & 112183.00 & 0.716733 & 0.135564 \\
\hline
\end{tabular}

